\title{
PINTURAS RUPESTRES Y CONTEXTOS ARQUEOLÓGICOS DE LA PRECORDILLERA DE ARICA (EXTREMO NORTE DE CHILE)
}

\author{
Marcela Sepúlveda, ${ }^{1}$ Magdalena García, ${ }^{2}$ Elisa Calás, ${ }^{3}$ Carlos Carrasco ${ }^{4}$ y Calogero Santoro
}

\section{* Introducción}

Resumen

Las evidencias de los sitios Pampa El Muerto 3 (PM-3), Pampa El Muerto 8 (PM-8) y Tangani I (TAN-1) permiten reafirmar que el arte rupestre de la precordillera en el extremo norte de Chile se asocia a una colonización más bien tardía de este espacio, hace 7000 años AP. Su ocupación por cazadores recolectores se intensificó hacia fines del Arcaico (ca. 6000-3700 años AP) perdurando hasta el Formativo Tardío (ca. 1500 años AP), y luego reiterarse en los períodos Intermedio Tardío y Tardío (800-500 años AP). En el Arcaico Tardío destaca un paisaje cultural común para el extremo norte de Chile y sur de Perú evidenciado por pinturas rupestres naturalistas en aleros rocosos. Las evidencias líticas, vegetales y arqueofaunísticas excavadas en estos lugares dan cuenta de actividades temporales, por lo que interpretamos los sitios con pinturas como campamentos logísticos estacionales. Además de articular diferentes pisos ecológicos, las poblaciones arcaicas tuvieron una movilidad horizontal precodillerana que unía toda el área situada entre 2500 y 3800 m.snm, cuando en la costa, valles bajos y subárea Circumtiticaca, simultáneamente, ocurrían otros procesos de complejización social.

Palabras claves: pinturas rupestres - estilo naturalista - movilidad precordillera - norte de Chile. (PM-8) and Tangani I (TAN-1) allow reaffirming that rock art found at the foothills of northern Chile is synchronic with a late colonization of this zone, $7000 \mathrm{BP}$. Its occupation by hunter-gatherers was intensified towards the end of the Archaic (ca.6000-3700 years BP), continued until the Late Formative (ca. 1500 years BP), and reemerged during Late Intermediate and Late periods (800-500 years BP). Throughout the Late Archaic phase the creation of a common cultural landscape for northern Chile and southern Peru is evidenced by rock art paintings naturalistic on the walls of rock shelters. Lithics, archaeological plant and bones remains indicate temporary domestic activities. Thus rock art painting sites are interpreted as seasonal logistical camps. Consecutively, more than articulating different ecological floors, these sites evidence horizontal mobility in foothills between 2500 and 3800 $\mathrm{m}$.asl, in times of increased complexity in coastal and low valleys of the region and the Circumtiticaca subarea.

Key words: rock art painting - naturalistic style - mobility - foothills northern Chile.
En América, el hallazgo de materias colorantes en contextos arqueológicos de fines del Pleistoceno se ha vuelto más común en los últimos años (Stafford et al. 2003; Salazar et al. 2011). Sin embargo, la falta de asociaciones contextuales bien definidas limita las posibilidades de precisar el uso de estos pigmentos, los que pudieron emplearse en la realización de pinturas rupestres, trabajo de pieles, y posiblemente, como pintura corporal.

En la región andina sur peruana, ciertas representaciones rupestres de estilo o tradición naturalista han sido vinculadas a grupos de cazadores recolectores del Arcaico Temprano (10.500-9500 AP) o primeras evidencias de poblamiento en la zona andina (Muelle 1969; Muelle y Ravinés 1986; Lavallée 1995; Guffroy 1999). Sin embargo, esta atribución cronológica sigue siendo tentativa dada la falta de dataciones directas sobre las pinturas, excavaciones de contextos asociados y la vinculación de esos resultados con las pinturas rupestres. A esto se suma que las cuevas y aleros donde se hallan estas pinturas fueron recurrentemente utilizadas desde el Arcaico hasta épocas recientes. Finalmente, el arte rupestre fue una práctica realizada a lo largo de varios milenios, por lo que los paneles registrados hoy día pueden presentar superposiciones de épocas distintas.

En la década de 1970, las pinturas de la precordillera de Arica (2500 a 3800 m.snm) del extremo norte de Chile constituyeron un importante objeto de estudio, definiéndose el denominado "estilo Sierra de Arica".

Recibido: febrero 2013. Aceptado: agosto 2013.

\footnotetext{
1 Departamento de Antropología, Universidad de Tarapacá, 18 de Septiembre 2222 - Casilla 6D, Arica, CHILE. Email: msepulveda@uta.cl/ marcelaasre@gmail.com.
} 
Cronológicamente y pese a encontrarse material lítico posiblemente asociado a épocas previas, este estilo fue entonces atribuido al período Agroalfarero Tardío (1000-1450 DC) (Niemeyer 1972; Mostny y Niemeyer 1983). De acuerdo a estos autores, la producción de las pinturas se habría realizado en el marco de ceremonias "mágico-religiosas" (Niemeyer 1972: 100; Schiappacasse y Niemeyer 1996). No obstante, posteriores análisis realizados en las décadas de 1980 y 1990 , distinguieron dos patrones en el "estilo sierra de Arica": uno atribuido a grupos cazadores recolectores del Arcaico (Santoro y Chacama 1982; Santoro y Dauelsberg 1985), y otro relacionado a la ocupación tardía de la región y a la movilidad caravanera (Muñoz y Briones 1996).

Estos estudios sirvieron de base para desarrollar, a partir del 2006 , una investigación orientada a revisar la definición estilística del "estilo sierra de Arica" y precisar la existencia de posibles variantes o subconjuntos para las pinturas de aleros de la precordillera del extremo norte de Chile. Específicamente siguiendo criterios de contraste, buscamos identificar la existencia de relaciones, variabilidad y estructura en los diseños y su organización de modo de definir patrones de organización cultural (Gallardo 1996). En términos interpretativos, apelamos, pese a sus limitaciones, a criterios de contigüidad, a las asociaciones espaciales entre contexto y arte rupestre (Gallardo 1996). En este caso particular, presentamos los resultados de las excavaciones de tres aleros: Pampa El Muerto 3 (PM-3), Pampa El Muerto 8 (PM-8) y Tangani 1 (TAN-1) (Figura 1). El análisis de los materiales líticos, vegetales y arqueofaunísticos permite precisar el tipo de actividades realizadas en los aleros y su temporalidad. Nueve fechados $\mathrm{C}^{14}$-AMS contribuyen a discutir la ubicación cronológica de estas ocupaciones. Finalmente, se evalúan estos resultados a

\footnotetext{
2 Programa Doctorado en Antropología, Universidad Católica del Norte. Gustavo Le Paige 380, San Pedro de Atacama, CP 1410000 , CHILE.Email: manegarciab@yahoo.com.

3 Colegio de Arqueólogos. Condominio Doña Isidora, Parcela 28, Curacaví, CHILE. Email: elisa.calas@gmail.com.

4 Colegio de Arqueólogos. Santa Victoria 45, Santiago, CHILE. Email:c_acg@yahoo.com.

5 Instituto de Alta Investigación, Universidad de Tarapacá, Antofagasta 1520, Casilla 6D, Arica, CHILE. Email: calogero_santoro@yahoo.com.
}

la luz de la información disponible para el área andina sur peruana.

\section{* Pampa El Muerto y Tangani en el extremo NORTE DE CHILE}

La precordillera o sierra del extremo norte de Chile constituye la antesala de la alta cordillera de los Andes por su vertiente occidental. Se trata de una franja angosta ( 20 a $35 \mathrm{~km}$ de ancho) que comprende los pisos ecológicos vegetacionales de prepuna situado entre los 2500 y 3300 m.snm y el piso de puna, tolar o matorral bajo entre los 3300 y 3800 m.snm (Villagrán et al. 1982; Villagrán y Castro 2004; Muñoz y Bonacic 2006). En la precordillera destaca el nacimiento de varios ríos que descienden hasta el océano Pacífico por profundas quebradas las que, orientadas en sentido este-oeste, contribuyeron notablemente a la movilidad de los grupos humanos desde tiempos prehispánicos, entre las zonas de tierras altas (altiplano y precordillera) y bajas (valles y costa).

La reciente georreferenciación de los sitios indica que la mayoría de los aleros con pinturas se localiza en la interfase entre los pisos de prepuna y puna (Sepúlveda et al. $2013 \mathrm{Ms}$ ) (Figura 1). Actualmente, la prepuna presenta condiciones áridas, con precipitaciones de intensidad variable ( 60 a $100 \mathrm{~mm}$ promedio al año) y caídas únicamente en los meses de verano (entre diciembre y marzo). Este aporte de agua contribuye a mantener una vegetación arbustiva estacional y algunos animales, principalmente guanacos (Lama guanicoe); sin embargo, resulta ser una zona, en general, poco atractiva para las comunidades indígenas pastoriles de la región (Villagrán et al. 1982, 1999; Latorre et al. 2005; Holmgren et al. 2008). El tolar o matorral bajo presenta la mayor cantidad y variedad vegetacional del norte del país (Villagrán y Castro 2004). Se caracteriza por formaciones arbustivas de hojas resinosas y persistentes (Muñoz y Bonacic 2006), debido a la mayor cantidad de precipitaciones $(\geq 100 \mathrm{~mm})$ esencialmente estivales, a la baja concentración de oxígeno y dióxido de carbono en el aire, la baja humedad relativa y la alta radiación solar (Muñoz y Bonacic 2006). A esta vegetación, se suma una importante variedad de fauna nativa además del guanaco, como la taruca (Hippocamelus antisensis), el quirquincho (Zaedius pichiy) y la perdiz de la puna (Tinamotis pentlandii), entre otros. 


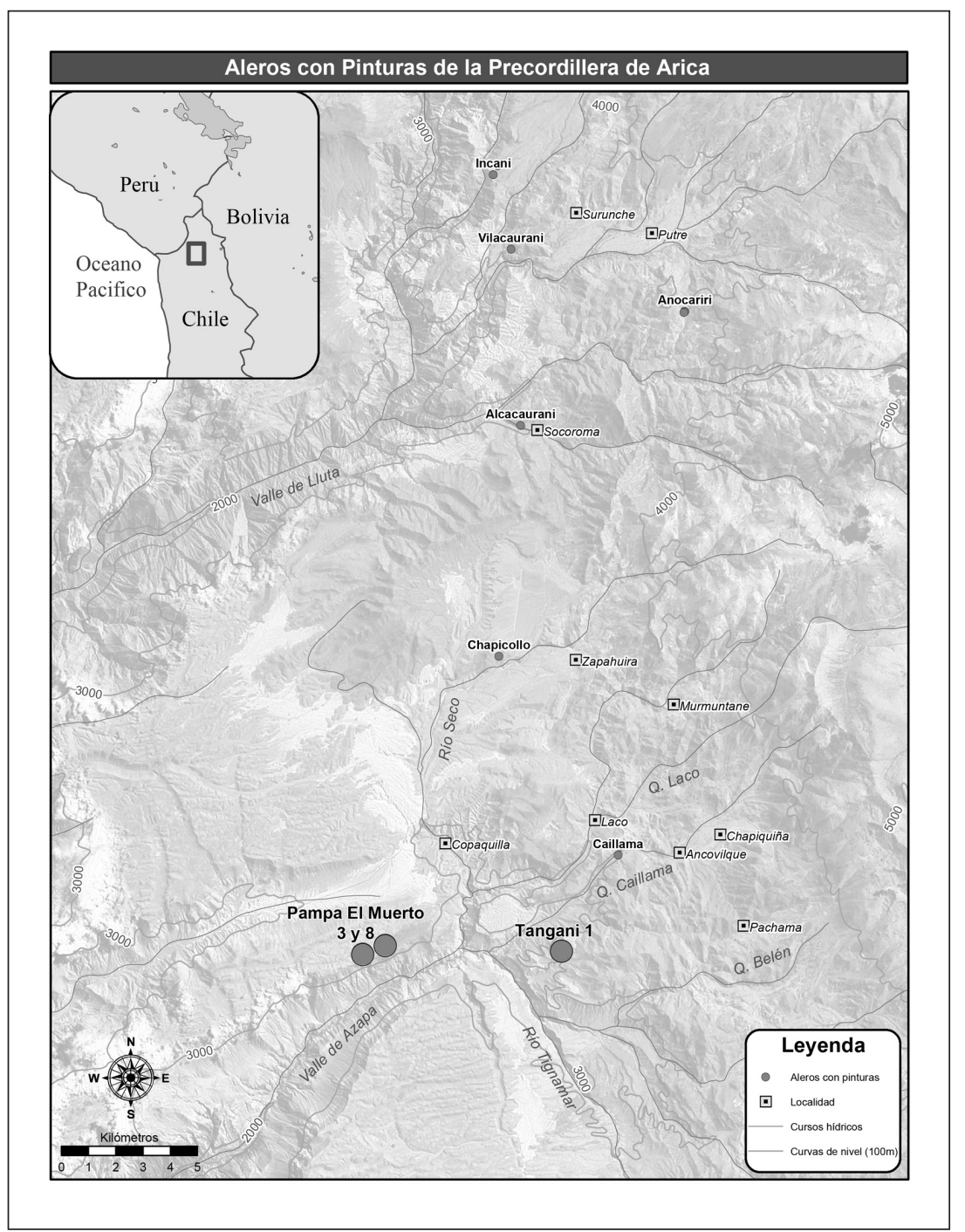

Figura 1. Mapa de localización de los sitios estudiados (PM-3, PM-8 y TAN-1) en el norte de Chile.

El panorama actual contrasta con la información paleoecológica de la región norte del desierto de Atacama, ubicada entre Arequipa y el Loa $\left(16^{\circ}-21^{\circ}\right.$ Lat. S.). Ésta muestra varios episodios de cambio desde finales del Pleistoceno y durante todo el Holoceno. En efecto, estudios paleoclimáticos recientes señalan que con posterioridad al último máximo glacial (17.000-9500 años cal. $\mathrm{AP})$, las condiciones fueron mucho más húmedas que las actuales. No obstante, en el Holoceno Temprano, a partir de 9000 años AP, las condiciones comenzaron a ser más áridas, con un episodio de mayor humedad entre 7000 a 4500 años cal. AP. Hacia finales del Holoce- no las condiciones vuelven a ser un poco más secas, con un leve incremento de las precipitaciones entre $2000 \mathrm{a}$ 1000 años cal. AP (Latorre et al. 2005). Por su parte, los estudios paleoclimáticos de Holmgren y colaboradores (2008) en el piso prepuneño cercano a Arequipa (2350 y $2850 \mathrm{~m} . \mathrm{snm}$ ) indican que, en los últimos 3000 años, las condiciones fueron en realidad mucho más estables que lo indicado por Latorre y colaboradores (2005). En efecto, Holmgren y su equipo (2008) reconocen una vegetación xerófila de arbustos anuales y cactus relativamente constante durante todo el Holoceno, con un particular y puntual aumento triplicado de taxones en 
el Holoceno Medio, aproximadamente en torno a 6700 años cal. AP.

Esta información resulta particularmente relevante para comprender la ocupación de los pisos de prepuna y puna de la precordillera del extremo norte de Chile, que podría en parte explicar la ausencia, hasta ahora, de ocupación humana previa al Holoceno Medio, pues solo a partir de esa época se evidencian nuevamente condiciones más húmedas y más benéficas desde el punto de vista vegetacional. Como indica el registro arqueológico actual, a diferencia del altiplano, la puna y la costa donde existen ocupaciones fechadas hacia 11.000 y 13.000 años cal. AP, los antecedentes más antiguos para la precordillera se evidencian a partir del Arcaico Medio, entre 80006000 años (fechas no calibradas; Santoro y Núñez 1987; Núñez y Santoro 1988; Santoro 1989; Sandweiss 2003; DeFrance y Umire 2004; Santoro y Latorre 2009; Lavallé et al. 2011; Núñez y Santoro 2011; Osorio et al. 2011; Santoro et al. 2012; Ugalde et al. 2012; Latorre et al. 2013). Por ello, resulta de interés el análisis de los sitios que integran este estudio (PM-3, PM-8 y TAN-1), pues como aleros con pinturas pueden ayudar a comprender los procesos sociales vinculados a la ocupación humana de la precordillera y su posible relación con los cambios climáticos registrados en el desierto de Atacama.

\section{* Definiciones estilísticas de las PINTURAS RUPESTRES}

El análisis de las pinturas de varios sitios de la precordillera ha permitido precisar varias distinciones estilísticas siguiendo criterios relativos a los tipos de figuras zoomorfas y antropomorfas ${ }^{6}$ y la composición de paneles. El análisis de 990 figuras registradas en 17 sitios (Sepúlveda 2008, 2011; Sepúlveda et al. 2010) ha permitido distinguir dos grupos estilísticos (sensu Aschero 2001).

El Grupo Estilístico I (GEı) se inserta dentro de la tradición naturalista. Desde su definición en la década de 1970 (Niemeyer 1972), éste ha sido comparado con las pinturas del sur de Perú (Guffroy 1999), del desierto de Atacama (Núñez et al. 1997, 2006) y del Noroeste Argentino (Yacobaccio et al. 2008). En la muestra estu-

\footnotetext{
6 Para descripción de variables empleadas ver Sepúlveda (2011).
}

diada este Grupo presenta dos variantes o estilos, cuya distinción se establece, principalmente, en las composiciones escénicas de los paneles. El primer Estilo (GE1-1) está constituido por camélidos pintados en los que destacan sus rasgos anatómicos, como la línea del vientre y las articulaciones de las extremidades inferiores. Estos animales alcanzan tamaños de hasta $60 \mathrm{~cm}$ y participan de escenas complejas que integran una gran cantidad de camélidos similares y dispuestos ya sea alineados o de forma aleatoria (Figura 2a). Además, se relacionan espacialmente a antropomorfos que suelen ser bastante más pequeños (menos de $10 \mathrm{~cm}$ ), representados por trazos lineales simples, sin animación y de frente, en grupos alineados unos al lado de los otros o rodeando un animal (Figura 2b). En este conjunto predomina el color rojo, aunque se observa también el uso del negro y el amarillo. El segundo Estilo (GE1-2) reúne camélidos con rasgos anatómicos que igualmente destacan el vientre, y más raramente en las patas. En este segundo estilo, los camélidos y los antropomorfos suelen representarse con tamaños más equitativos, aunque generalmente de menor dimensión que en el primer estilo. Los paneles integran pocas figuras y, a diferencia del estilo anterior, aquí son recurrentes las escenas animadas con camélidos "perseguidos" por antropomorfos lineales de perfil con animación y portando apéndices que podrían representar armas como lanzas o arcos (Figura 2c). Las escenas de caza con distintas variantes son comunes en este grupo GEı (Dudognon y Sepúlveda 2013).

Además, el Grupo Estilístico 2 (GE2) se refiere a camélidos sin rasgos naturalistas, de cuerpo rectangular y con patas representadas por simples trazos (Figura 3a). Estos animales pueden o no estar unidos por una cuerda a una figura antropomorfa, por lo que puede ser interpretada como imagen de un "pastor". En estas escenas, las figuras suelen ser, en general, de pequeño tamaño, menor a $8 \mathrm{~cm}$ (Figura 3b).

Otro conjunto de figuras, y al cual no hemos prestado aún suficiente atención, hace referencia a diseños y motivos geométricos simples tales como círculos concéntricos, líneas en zigzag u ondulantes, y otros más complejos, tales como cuadrados con los bordes opuestos curvos hacia dentro y un cuadrado más pequeño en su interior, cuadrados rodeados de puntos y con círculos en su interior. Por ahora, estas representaciones apare- 


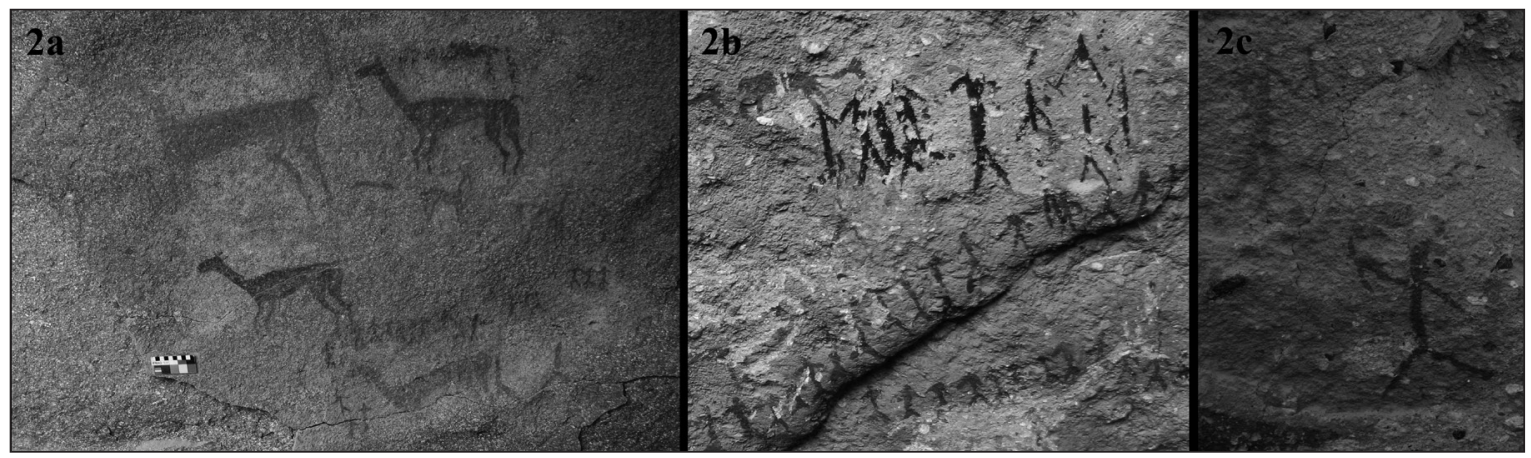

Figura 2. Pinturas rupestres del primer Estilo: a) GE1-1, panel PM-8; b) GE1-1, detalle panel principal de TAN-1; c) GE1-2, detalle de panel de TAN-3.

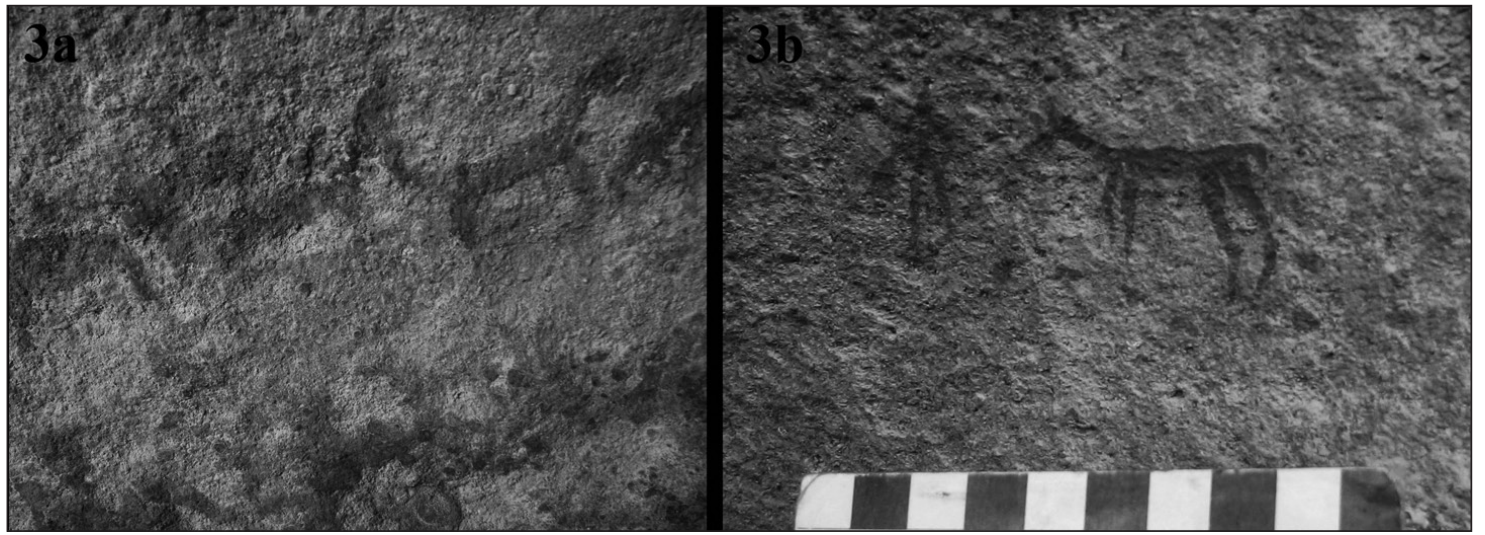

Figura 3. Pinturas rupestres del segundo Grupo Estilístico GE2: a) Detalle de panel de TAN-11; b) Detalle de panel de TAN-15.

cen indistintamente en paneles aislados o en paneles asociados a GE1.

En los paneles de PM-3 y PM-8 priman las representaciones y composiciones del estilo GE1-1, con camélidos naturalistas, en colores negro y rojo. En el único panel de PM-8, las figuras antropomorfas son minoritarias y aparecen sobrepuestas y rodeando un camélido de gran tamaño. En PM-3, en cambio, si bien el panel principal se asemeja estilísticamente al de PM-8, los otros paneles situados sobre la pared opuesta son de una tonalidad roja más clara y refieren exclusivamente a motivos geométricos. En TAN-1, aunque el panel es extraordinariamente extenso ( $5 \mathrm{~m}$ de largo), las pinturas se concentran en su sector izquierdo, justamente donde la pared se curva horizontalmente conformando parte del techo del alero. En general, las pinturas representan escenas superpuestas conformadas por alineamientos de camélidos, uno detrás del otro, y antropomorfos representados por simples trazos lineales dispuestos de frente, sin animación, unos al lado de los otros. Las figuras son de menor tamaño que en PM-3 y PM-8. La composición es también más compleja que en esos sitios, dada la yuxtaposición y superposición de escenas, el uso de diferentes colores y tonos y variaciones estilísticas. Es posible que este panel sea producto de distintas visitas al sitio ocurridas en diferentes momentos o períodos. En este sitio se encuentran consecuentemente representaciones atribuidas al estilo GE1-1, GE1-2 y GE-2. Se registran también grabados de camélidos y motivos geométricos sobrepuestos a las pinturas, más semejantes a GE-2. 


\section{* Metodologías de anÁlisis de los CONTEXTOS ARQUEOLÓGICOS ASOCIADOS}

Las excavaciones realizadas en los sitios PM-3, PM-8 y TAN-1 (Figuras 4a, 4b y 4c) tuvieron por objetivo establecer relaciones contextuales para las pinturas rupestres, específicamente, el tipo de actividades realizadas en los aleros, así como su temporalidad. En general, los sitios presentan depósitos de poca profundidad, una característica común a gran parte de los aleros con pinturas de la prepuna (Niemeyer 1972; Schiappacasse y Niemeyer 1996). La excavación se realizó por unidades de 1xı m y pozos de evaluación de $0.25 \times 0.25 \mathrm{~m}$, sumando en total: $5 \mathrm{~m}^{2}$ en PM-3, $2.0625 \mathrm{~m}^{2}$ en PM-8 y $2 \mathrm{~m}^{2}$ en TAN-1. La excavación se realizó siguiendo las capas naturales y niveles artificiales de 5-10 cm. Todo el material recuperado fue tamizado con malla de $2 \mathrm{~mm}$, de modo de recuperar microdesechos líticos y macrorrestos vegetales (frutos y semillas). Además, se tomaron muestras de suelo para flotación relativas a 1 lt por cada nivel estratigráfico excavado.

En relación al material lítico se analizaron macroscópicamente 2249 piezas (PM-3, $n=1274 ; \mathrm{PM}-8, \mathrm{n}=274$ y TAN$1, n=701$ ) para evaluar los patrones de uso y descarte de los materiales. Se identificaron las etapas de la secuencia de reducción presentes en cada conjunto. Se caracterizó la funcionalidad de los sitios a partir de las variables litológicas (identificación macroscópica de materias primas), tecnológicas y morfológicas de piezas formatizadas y derivados de talla con modificaciones (Bate 1971; Aschero 1983 Ms). Se definieron además categorías tecnológicas de desechos mediante la observación y medición macroscópica de tres variables: tipo de talón; tamaño máximo y conservación de corteza (Andrefsky 1998).

Los materiales orgánicos, vegetales y óseos no fueron cuantiosos, principalmente debido a su baja preservación por efecto de las lluvias estivales, aunque también por el carácter temporal de las ocupaciones. Los análisis vegetales se orientaron a determinar la diversidad de especies representadas, así como su distribución espacial y estratigráfica en cada uno de los aleros. Asimismo, fue importante registrar el órgano representado de la planta (semilla, fruto, tallo, etc.), así como las distintas formas de preservación (carbonizado, deshidratado) para la comprensión de los contextos de consumo. El análisis integró tanto el material obtenido por harnero, así como el recuperado por flotación. En relación a éste, en PM-3 se flotó un total de 37.56 lt de sedimento, en PM-8, 9.06 lt y en TAN-1, 50.32 lt (García y Sepúlveda 2011). Los restos de plantas fueron analizados macroscópicamente utilizando lupa binocular (0.7-4.5X).

El análisis del material arqueofaunístico consideró una muestra total de 3214 restos (PM-3, n=1812; PM$8, \mathrm{n}=772$ y TAN-1, $\mathrm{n}=630$ ). La asignación anatómica y taxonómica de los restos de camélidos se realizó mediante esqueletos de referencia y criterios métricos, en particular, de los huesos cortos (astrágalo, tarsos y carpos) (Cartajena 2002). Para los demás taxones, mayoritariamente roedores, se utilizaron tanto esqueletos de referencia como guías morfológicas (Reise 1973; Mann 1978). Adicionalmente, se realizó una estimación de la composición etaria de los restos de camélidos con tres fuentes de información: erupción y desgaste dentario, y fusión epifisiaria (Kaufmann 2009). Los especímenes no identificados fueron divididos en tres grandes categorías analíticas: hueso plano, fragmento mínimo y hueso largo. Dentro de éstas, cuando fue posible, se utilizaron dos subcategorías: mamífero grande (camélidos) y animales pequeños (roedores, marsupiales y aves). En cada categoría se consignó el número de restos con huellas de termoalteración. Además, se efectuaron medidas cuantitativas: NISP, NUSP, MNI, MNE y Ri (Grayson 1984; Andrews 1990; Lyman 1994; Mengoni 1999). Finalmente, las modificaciones observadas en la superficie de los restos óseos fueron divididas de acuerdo a su agente productor: naturales y culturales.

\section{* Resultados}

\section{Resultados del análisis lítico}

El material lítico muestra comportamientos similares en los tres sitios, con conjuntos compuestos principalmente por desechos de talla, y en menor medida, instrumentos a los que se les pudo asignar una categorización morfofuncional (artefactos formatizados y derivados con modificaciones).

Así, en los tres conjuntos predominan los derivados de derivados (DD) o derivados de matrices, con escasa 


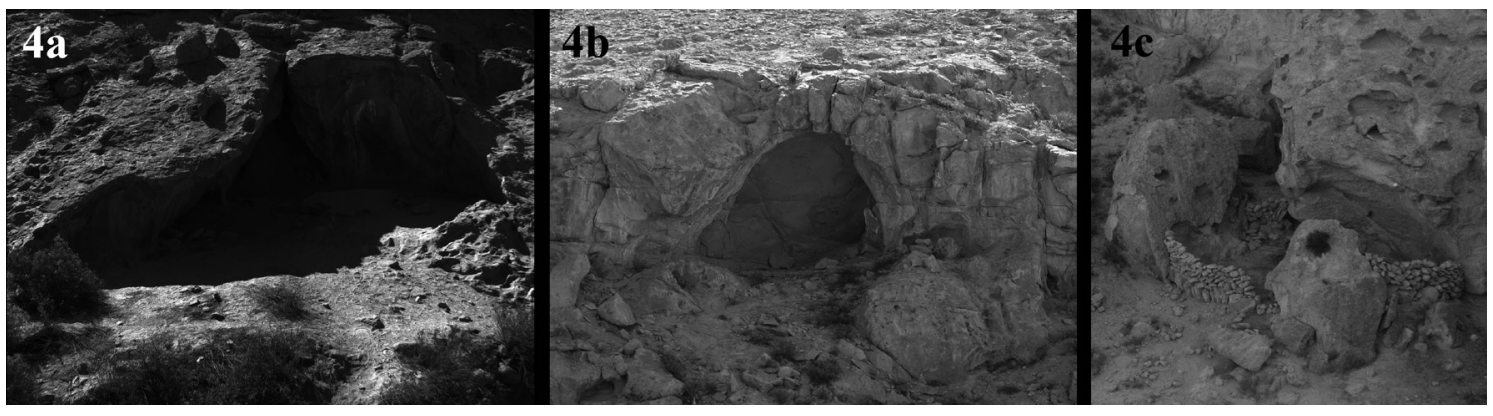

Figura 4. Fotografías de aleros estudiados: a) PM-3; b) PM-8; y c) TAN-1.

\begin{tabular}{|c|c|c|c|c|c|c|c|c|}
\hline Categoría & PM-3 & PM-8 & TAN-1 & PM-3 & PM-8 & TAN-1 & \% Total & $\mathbf{N}^{\circ}$ Total \\
\hline DB & $192 \%$ & $1.10 \%$ & $8.73 \%$ & 24 & 3 & 60 & $3.94 \%$ & 87 \\
\hline DD & $97.43 \%$ & $96.70 \%$ & $62.15 \%$ & 1215 & 264 & 427 & $86.36 \%$ & 1906 \\
\hline DN & $0.64 \%$ & $2.20 \%$ & $10.33 \%$ & 8 & 6 & 71 & $3.85 \%$ & 85 \\
\hline ND & $0.00 \%$ & $0.00 \%$ & $18.78 \%$ & - & - & 129 & $585 \%$ & 129 \\
\hline Total & $100.00 \%$ & $100.00 \%$ & $100.00 \%$ & 1247 & 273 & 687 & $100.00 \%$ & 2207 \\
\hline
\end{tabular}

Tabla 1. Frecuencia de material lítico por sitio.

frecuencia de piezas extraídas directamente de núcleos (DN), lo que corresponde a los momentos finales del proceso de talla. Se registran además, en menor medida, piezas derivadas de retoque bifacial (Tabla 1).

El reconocimiento macroscópico de las materias primas permitió identificar el uso mayoritario de rocas silíceas en todos los sitios (siendo la variedad de tonalidades claras las más destacadas), con $92 \%$ en PM-3, 89\% en PM-8 y $98 \%$ en TAN-1. Otras materias primas utilizadas, en bajas frecuencias, corresponden a rocas de grano grueso como andesita, basalto y riolita. La obsidiana, de origen externo, fue reconocida en un solo caso, por lo que su uso fue ocasional. En contraste, las otras materias primas, de origen local, fueron usadas con mayor frecuencia.

El análisis tecnológico de los desechos de talla también muestra un comportamiento similar, caracterizado por una alta incidencia de talla bifacial. Los talones facetados son los más frecuentes y en los sitios de Pampa del Muerto superan el 60\%. A esto se agrega la presencia de talones seudo-facetados derivados directamente de talla bifacial. Ambos tipos de desechos se vinculan a etapas

\begin{tabular}{|c|c|c|c|c|}
\hline Corteza & PM-3 & PM-8 & TAN-1 & Total \\
\hline Ausente & $99.84 \%$ & $98.53 \%$ & $98.40 \%$ & $99.23 \%$ \\
\hline Parcial & $0.08 \%$ & $0.73 \%$ & $1.31 \%$ & $0.54 \%$ \\
\hline
\end{tabular}

Tabla 2. Presencia de corteza en material lítico.

finales de reducción y "finiquitación" de instrumentos bifaciales. A este indicador se suman el alto porcentaje de piezas sin corteza (Tabla 2), y el predominio de tamaños pequeños, entre 1 y $2 \mathrm{~cm}$.

El conjunto de estos indicadores sugiere que a los sitios se ingresaron piezas obtenidas de derivados de núcleo y matrices avanzadas. El descarte corresponde principalmente a piezas derivadas de talla avanzada de matrices y finiquitación de instrumentos, predominando la talla bifacial con escasa presencia de talla monofacial y marginal.

En cuanto a los instrumentos formatizados, figuran 27 piezas provenientes de PM-3, solo una de PM-8 y tres 


\begin{tabular}{|l|l|c|}
\hline Sitio & \multicolumn{1}{|c|}{ Categoría morfofuncional } & Total \\
\hline PM-3 & Uso cortante & 12 \\
\cline { 2 - 3 } & Mano de moler & 1 \\
\cline { 2 - 3 } & Muesca & 1 \\
\cline { 2 - 3 } & No identificados & 7 \\
\cline { 2 - 3 } & Núcleo & 1 \\
\cline { 2 - 3 } & Preforma & 1 \\
\cline { 2 - 3 } & Puntas de proyectil & 3 \\
\cline { 2 - 3 } & Raspador & 27 \\
\hline \multirow{2}{*}{ Total } & & \\
\hline
\end{tabular}

Tabla 3. Frecuencias de categorías morfofuncionales en PM-3.

ejemplares recuperados desde la superficie de TAN-1. Esta diferencia puede deberse al tamaño de superficie excavada, donde el sitio que ofrece mayor número de ejemplares, fue excavado de manera más extensiva.

La única pieza formatizada proveniente del sitio PM-8 se recuperó en el nivel superficial de la unidad A2 y corresponde a un perforador de cuerpo diferenciado, elaborado sobre una lasca de roca silícea. Presenta talón natural y corteza parcial en el anverso, atributos no registrados en los otros sitios. Esta situación puede corresponder a la realización de actividades diferenciadas en PM-8, en relación a los otros, o al abandono circunstancial de este instrumento en situación de transporte, sin que signifique necesariamente que el sitio haya tenido un uso distinto.

En PM-3 se registra una amplia variedad de artefactos, entre los que predominan los de uso cortante (Tabla 3), vinculados posiblemente a actividades de faenamiento de presas o preparación de alimentos. También con frecuencias importantes figuran aquellos que no pudieron ser identificados por sus condiciones de descarte (alto grado de fracturas). De los 12 instrumentos de uso cortante, ocho se encuentran en estado de descarte completo, mientras el resto se presenta en fragmentos proximal, distal y no identificado. Todos ellos fueron elaborados en lascas de rocas silíceas. Once son de tecnología marginal y solo uno de tecnología bifacial (Figura 5a). Cinco de ellos presentan dos bordes de uso activos y siete solo uno. Entre los bordes, resultan más frecuentes los rectos $(n=7)$ y los convexos $(n=4)$, mientras que solo uno es recto y cóncavo.
Las puntas de proyectil suman tres y fueron elaboradas en rocas silíceas sobre matrices no identificadas con tecnología bifacial (Figura 5b). Dos de ellas se hallan completas y una tercera corresponde a un fragmento distal o ápice. Sus estados de descarte completos, aunque con deficiencias técnicas, y fracturados, sugieren que su elaboración, o al menos finiquitación, se estaría desarrollando en el mismo sitio, y pueden heber sido abandonados por alguna insuficiencia tecnológica.

Los otros instrumentos se relacionan con actividades de procesamiento de alimentos o materias primas. Entre estos se identifica un raspador, una muesca y una mano de moler. La única mano de moler recuperada (PM-3, $\mathrm{Cl}_{1}$, Capa 1) corresponde a un guijarro completo de ignimbrita, con una única cara pulida de sección plana. La muesca (PM-3, $\mathrm{C}_{5}$, Capa 2, nivel 1) se depositó completa. Ésta fue elaborada sobre una lasca de roca silícea con tecnología marginal simple, con la modificación del borde activo restringida (menos el 25\% del borde de uso modificado). Este instrumento puede corresponder a un raspador estrecho para ser utilizado en superficies convexas restringidas, posiblemente vinculado a la preparación de astiles.

Finalmente, en TAN-1 se registran tres instrumentos recolectados solo de la superficie del sitio. Sus materias primas no se corresponden con las utilizadas en los artefactos recuperados de la excavación. La primera pieza, elaborada sobre una lasca con tecnología bimarginal doble, presenta los bordes convexos, extendidos y regulares, con un ángulo más bien abrupto. Podría tratarse de un artefacto de uso cortante. La segunda pieza corresponde a una punta de proyectil de $35 \mathrm{~mm}$, elaborada en tecnología bifacial. Tiene forma lanceolada con bordes convexos y extendidos y base convexa. La tercera pieza corresponde a un núcleo de tipo unidireccional pequeño (36 mm de longitud máxima).

En resumen, la talla bifacial fue la más frecuente en los sitios y pudo estar orientada, principalmente, a la elaboración de puntas de proyectil, utilizadas por parte de cazadores en tránsito, que ocuparon temporalmente los aleros. En estos sitios se habrían desarrollado, también, actividades de faenamiento o procesamiento, evidenciadas por instrumentos de uso cortante, y en menor medida, de raspadores. El uso recurrente de una misma materia prima, la que se distribuye, además, de forma similar tanto espacial 


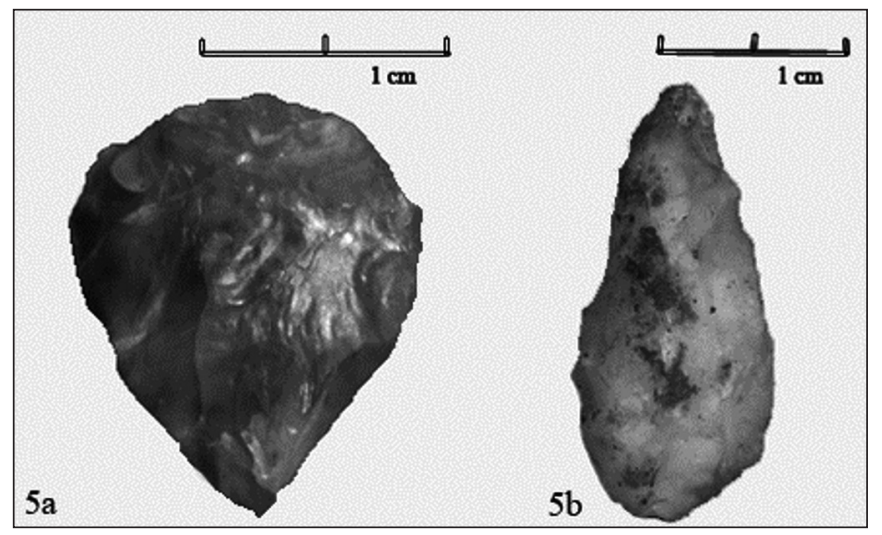

Figura 5. a) Instrumento cortante de tecnología bifacial (PM-3, Unidad B4, nivel superficial); b) Punta de proyectil (PM-3, Unidad D2. Capa III, nivel 1).

\begin{tabular}{|c|c|c|c|c|c|c|}
\cline { 2 - 7 } \multicolumn{1}{c|}{} & \multicolumn{2}{c|}{ Pampa El Muerto 3 } & \multicolumn{2}{c|}{ Pampa El Muerto 8 } & \multicolumn{2}{c|}{ Tangani 1 } \\
\cline { 2 - 7 } \multicolumn{1}{c|}{} & $\begin{array}{c}\text { Densidad } \\
\text { máxima }\end{array}$ & $\begin{array}{c}\text { Densidad } \\
\text { promedio }\end{array}$ & $\begin{array}{c}\text { Densidad } \\
\text { máxima }\end{array}$ & $\begin{array}{c}\text { Densidad } \\
\text { promedio }\end{array}$ & $\begin{array}{c}\text { Densidad } \\
\text { máxima }\end{array}$ & $\begin{array}{c}\text { Densidad } \\
\text { promedio }\end{array}$ \\
\hline Opuntia sp. & 15.06 & 2.8 & 55 & 11.81 & 37.69 & 8.25 \\
\hline aff. Oreocereus spp. & 0 & 0 & 1.45 & 0.22 & 8.46 & 0.85 \\
\hline
\end{tabular}

Tabla 4. Densidad de semillas de cactáceas en los sitios estudiados.

como estratigráficamente, sugiere el aprovechamiento de las mismas áreas de aprovisionamiento. Esta recurrencia puede vincularse con circuitos de movilidad de cierta regularidad, lo que se ve reforzado por la leve intensidad de ocupación registrada en los asentamientos.

\section{Resultados del análisis vegetal}

Las semillas de cactáceas están presentes en los tres depósitos analizados: 105 semillas de Opuntia sp. en PM3, 107 en PM-8, junto a dos ejemplares de aff. género Oreocereus spp., mientras que TAN-1 es el contexto que evidencia la mayor concentración de ambos taxones: con 415 (66\%) y 43 (96\%), respectivamente (Tabla 4).

Las cactáceas presentan un comportamiento diferencial en la distribución estratigráfica en los distintos aleros, lo que podría estar determinado por el carácter e intensidad de las ocupaciones. A nivel de sitio, sin embargo, el comportamiento es similar en las distintas unidades excavadas, otorgándole una fuerte coherencia estratigráfica interna a los depósitos. En las distintas unidades excavadas $\mathrm{PM}_{-3}$ ( $\mathrm{C}_{1}, \mathrm{C}_{5}$ y D2), las semillas de Opuntia tienden, en general, a aumentar hacia los niveles intermedios (rasgos y niveles de la Capa 2) donde se constata la mayor densidad (15.06 sem/lt). Las frecuencias disminuyen progresivamente hacia los niveles inferiores, llegando a la ocupación inicial con un índice de densidad o (Capa 4) (García y Sepúlveda 2011). En PM-8, la tendencia distribucional es diferente, ya que la mayor densidad de semillas de cactáceas, tanto Opuntia sp. como aff. Oreocereus spp., se encuentran asociadas a los niveles superiores ( 55 $\mathrm{sem} / \mathrm{lt}$ y $1.45 \mathrm{sem} / \mathrm{lt}$, respectivamente) de la única unidad excavada (B4) (García y Sepúlveda 2011). En TAN-1 la distribución estratigráfica de estos elementos es más errática en ambas unidades excavadas ( $\mathrm{C}_{4}$ y $\left.\mathrm{D}_{4}\right)$, aunque como en PM-3 la mayor densidad se encuentra en los niveles intermedios (rasgos y niveles de la Capa 2 con índices $37.69 \mathrm{sem} / \mathrm{lt}$ y $8.46 \mathrm{sem} / \mathrm{lt}$, respectivamente). Estas frecuencias disminuyen hacia los niveles superiores e iniciales, que a su vez estaban intercalados con capas densas de ocupación y otras completamente estériles (García y 


\begin{tabular}{|c|c|c|c|c|}
\hline Nombre común & Nombre científico & Evidencia & Estación & Usos etnográficos \\
\hline \multirow[t]{2}{*}{ Yuyo } & Familia Chenopodium sp. & Semilla & Verano-otoño & $\begin{array}{c}\text { Alimenticio, medicinal, } \\
\text { forraje }\end{array}$ \\
\hline & Chenopodiaceae & Semilla & Verano-otoño & $\begin{array}{c}\text { Alimenticio, medicinal, } \\
\text { forraje }\end{array}$ \\
\hline $\begin{array}{l}\text { Pichaja, tunilla, quisco, } \\
\text { cardón blanco }\end{array}$ & $\begin{array}{c}\text { aff Oreocereus spp. } \\
\text { Cactaceae }\end{array}$ & Semilla & Verano-otoño & Alimenticio \\
\hline $\begin{array}{c}\text { Jalala, tuna, pegapega, } \\
\text { kume, puskayo }\end{array}$ & Opuntia sp. & Semilla & Verano-otoño & $\begin{array}{l}\text { Alimenticio, medicinal, } \\
\text { forraje, tintóreo }\end{array}$ \\
\hline \multirow[t]{2}{*}{$\begin{array}{l}\text { Sikuya, k'isi, paja } \\
\text { blanca }\end{array}$} & $\begin{array}{c}\text { Stipa sp. } \\
\text { Poaceae/Graminae }\end{array}$ & Tallo y bulbo & Verano-otoño? & Forraje, constructivo \\
\hline & Familia Brassicaceae & Hoja & Anual & \\
\hline $\begin{array}{c}\text { Algarrobo, taracusa, } \\
\text { yali }\end{array}$ & $\begin{array}{l}\text { Prosopis sp. } \\
\text { Fabaceae }\end{array}$ & Semilla & Primavera & $\begin{array}{l}\text { Alimenticio, forraje, leña, } \\
\text { constructivo, medicinal }\end{array}$ \\
\hline Maíz & $\begin{array}{l}\text { Zeamays } \\
\text { Poaceae }\end{array}$ & Mazorca & Verano-otoño & $\begin{array}{c}\text { Alimenticio, forraje, leña, } \\
\text { medicinal }\end{array}$ \\
\hline
\end{tabular}

Tabla 5. Especies vegetales identificadas en los sitios PM-3, PM-8 y TAN-1. Usos según Villagrán y Castro (2004), Pardo y Pizarro (2005) y Novoa (2006).

Sepúlveda 2011). Esto permite inferir un uso cambiante de los frutos alimentarios.

En la actualidad, las distintas variedades de Opuntia (piskayo, jalajala, pegapega, kume, tuna) que crecen en la puna andina (2700-3000 m.snm) son rastreras y forman grandes cojines. Sus frutos, comestibles al natural, son de sabor ácido similar al limón y agradables para combatir la sed. Además se utilizan como medicina, ya sea como cicatrizante, disolución de cálculos, para el hígado, diabetes, vejiga, garganta, tos y fiebre, entre otros (Tabla 5) (Villagrán y Castro 2004; Pardo y Pizarro 2005; Novoa 2006). En cuanto a las especies de Oreocereus spp., también son frecuentes en la precordillera de Arica y Parinacota, y de Tarapacá. Sus frutos son carnosos y comestibles (O. leucotrichus y $O$. variicolor). Etnográficamente, existe información de uso para el Oreocereus leucotrichus - conocido como cactus blanco o tunilla-, en referencia al filamento blanco que la cubre y por la importancia alimenticia de sus frutos amarillos y sabor algo ácido, por lo que son comidos con sal (Hoffmann 1989; Villagrán y Castro 2004; Pardo y Pizarro 2005; Novoa 2006). Se recolectan durante los meses posteriores a las lluvias de verano. Esta clase de evidencia puede ser indicadora de estacionalidad, por lo que su amplia distribución estratigráfica en los aleros excavados podría acusar ocupaciones ocurridas, preferentemente, entre marzo y mayo, coincidente con la mayor disponibilidad de pasturas para todo tipo de animales.

Otras plantas presentes en Pampa El Muerto son algarrobo (Prosopis sp.) y maíz (Zea mays), actualmente ausentes en el entorno inmediato de los aleros. Los restos de algarrobo están representados en PM-8 a través de dos endocarpos asociados a la Capa 1. De esta manera, éstos serían descartados junto a la mayor concentración de Opuntia. El maíz, en cambio, representado por una mazorca completa y un grano carbonizado, aparece en los niveles superiores de PM-3, con lo cual sería posterior al predominio de los frutos de cactáceas, sugiriendo ocupación del alero en momentos posteriores o tardíos, coherente con la fecha obtenida de los niveles superiores de este sitio $(430 \pm 25 \mathrm{AP})$.

Se cuantificó un total de 199 unidades de semillas de la familia Chenopodiaceae, todas concentradas en TAN-1, dentro de las cuales un $71 \%$ se hallaron carbonizadas. Únicamente tres ejemplares de la Capa 2 pudieron vincularse con mayor certeza al género Chenopodium sp. (yuyo silvestre). Estos yuyos son abundantes en el entorno de los aleros; el consumo fresco de sus tallos, 


\begin{tabular}{|l|c|c|c|}
\hline \multicolumn{1}{|c|}{ Sitio } & Identificados & No identificados & Total \\
\hline Pampa El Muerto 3 & 180 & 1632 & 1812 \\
\hline Pampa El Muerto 8 & 504 & 269 & 773 \\
\hline Tangani 1 & 161 & 469 & 630 \\
\hline Total & 845 & 2370 & 3215 \\
\hline
\end{tabular}

Tabla 6. Resumen de restos arqueofaunísticos analizados por sitio.

pelándolos y descartando las inflorescencias donde se ubican las semillas, ha sido documentado etnográficamente (Villagrán y Castro 2004). Lo anterior podría constituir evidencia de otra clase de alimento consumido por los ocupantes del alero.

Por último, en TAN-1 se encontró un conglomerado vegetal compuesto por paja blanca (Stipa sp.) y hojas suculentas (familia Brassicaceae), plantas recurrentes en el entorno y de fácil recolección y transporte. Los restos muestran una apariencia similar a un nido de ave, de tamaño 50 x $60 \mathrm{~cm}$ y $15 \mathrm{~cm}$ de espesor, aunque sin evidencias de fecas, que constituyen un elemento diagnóstico para sostener esta interpretación. De este modo, nos parecen sugerentes los antecedentes entregados por Rodríguez (1996-1998) en relación a la presencia de camadas de Stipa sp. y Deyeuxia eminens en el alero Quebrada Seca 3, Antofagasta de la Sierra (Puna Meridional argentina) los cuales servirían para la preparación de pisos ocupacionales de superficie blanda, apta para el descanso. Un rasgo similar se registró en el sitio de Puxuma 2, caracterizado por una camada de fibra vegetal bajo dos entierros de niños, junto a un collar de cuentas, un pendiente de collar de cobre no fundido, material lítico y un mortero invertido, por lo que se debiera prestar mayor atención a este tipo de registro en los aleros precordilleranos (Núñez y Santoro 1988, 2011; Santoro 1989).

Finalmente, en todos los aleros se identificó otra serie de semillas como Krameria lappacea (tíkara hembra), Ambrosia artemisioides (tíkara macho), Adesmia sp., Cristaria dissecta (malvisco), Cistanthe sp., Ephedra sp. y semillas pertenecientes a la familia Verbenaceae. Dada su abundancia en el entorno de los sitios y la fácil dispersión de sus semillas por efecto del viento, se considera un ingreso natural en el contexto arqueológico.
En síntesis, los restos vegetales asociados a los aleros de Pampa El Muerto y Tangani se vinculan a alimentos recolectados del entorno inmediato como los frutos de cactáceas (Opuntia sp. y aff. Oreocereus spp.) y yuyos silvestres (chenopodiáceas), así como también provenientes de otros espacios un poco más alejados, como las vainas de algarrobo y el maíz, que debieron obtenerse en quebradas de mayor humedad, como Belén o Tignamar, más al sur. Por último, un uso diferente se encuentra representado a partir del conglomerado de pajas en TAN-1, el cual sugiere ser un buen soporte para el descanso.

\section{Resultados del análisis arqueofaunístico}

La muestra de restos óseos se distribuye desigualmente entre los sitios, concentrándose la gran mayoría en PM-3, con la mayor cantidad de unidades excavadas, mientras que los otros sitios, PM-8 y TAN-1, presentan cantidades similares entre ellos (Tabla 6). En PM-8, sin embargo, se logró identificar un alto porcentaje de especímenes (65.2\%), debido a su baja fragmentación, en comparación a los demás sitios: $9.93 \%$ en PM-3 y $25.55 \%$ en TAN-1. Un 35.86\% del conjunto muestra huellas de combustión, lo que podría corresponder a una práctica recurrente de descarte de restos óseos en fogones, utilizados eventualmente como combustible (Joly et al. 2005).

Se registró un total de 12 categorías taxonómicas, de las cuales seis corresponden a roedores con un $80.82 \%$ del total de la muestra identificada (Figura 6; Tabla 7); mientras que los camélidos indeterminados alcanzan un $15 \%$. Además de roedores y camélidos, se identificó un ave pequeña (1.8\%), yaca del norte (Thylamys pallidior, $0.6 \%$ ), taruca (Hippocamelus antisensis, $0.1 \%$ ) y Lacertilia (0.1\%). Dentro del conjunto de roedores predominan los cricétidos ( $58 \%$ del total de restos identificados) seguidos de vizcacha (Lagidium peruanum, 18.7\%). Como en casos 


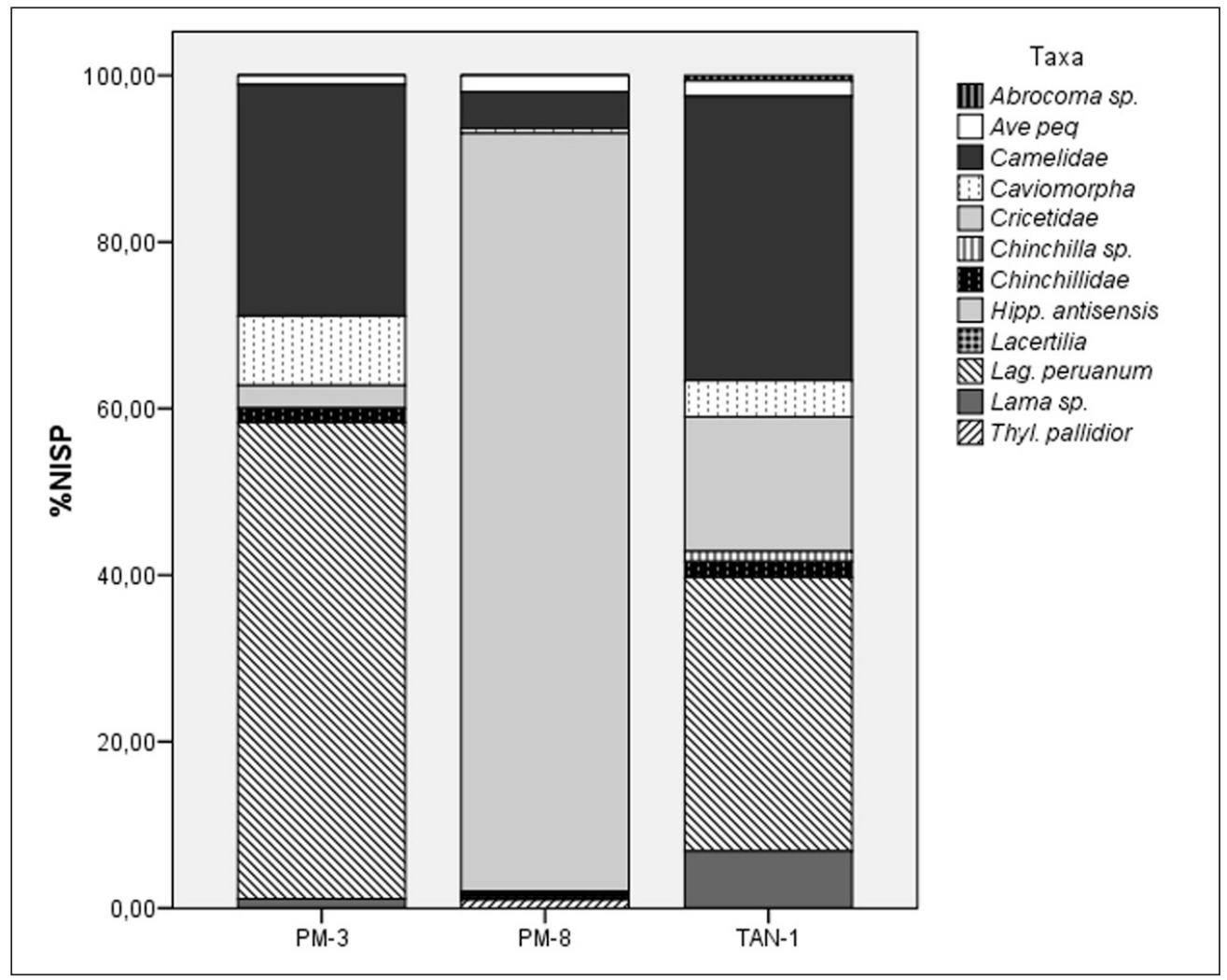

Figura 6. \%NISP del total de restos identificados.

\begin{tabular}{|c|c|c|c|c|}
\hline Taxón & Pampa El Muerto 3 & Pampa El Muerto 8 & Tangani 1 & Total \\
\hline Camelidae indet. & 50 & 22 & 55 & 127 \\
\hline Lama sp. & 2 & - & 11 & 13 \\
\hline Hippocamelus antisensis & - & 1 & - & 1 \\
\hline Lagidium peruanum & 103 & 2 & 53 & 158 \\
\hline Chinchilla sp. & - & - & 2 & 2 \\
\hline Chinchillidae & 3 & 1 & 3 & 7 \\
\hline Caviomorpha & 15 & 3 & 7 & 25 \\
\hline Abrocoma sp. & - & - & 1 & 1 \\
\hline Cricetidae & 5 & 459 & 26 & 490 \\
\hline Ave Peq. & 2 & 10 & 3 & 15 \\
\hline Lacertilia & - & 1 & - & 1 \\
\hline Thylamys pallidior & - & 5 & - & 5 \\
\hline Total & 180 & 504 & 161 & 845 \\
\hline
\end{tabular}

Tabla 7. 
anteriores, se nota una gran diferencia entre los sitios. En PM-3 y TAN-1 predomina la vizcacha, mientras que en PM-8 está prácticamente ausente, predominando los roedores cricétidos.

En términos culturales destacan dos taxones: en primer lugar la vizcacha, que predomina en casi todas las unidades y capas, y los camélidos. Ambos taxones fueron introducidos antrópicamente a los yacimientos, pues se evidencian especímenes quemados y con huellas de corte. Es posible que las vizcachas fueran cazadas en los alrededores y luego trasladadas completas al yacimiento, ya que se registraron casi todas las partes del esqueleto, con la excepción de vértebras y otros elementos pequeños como las falanges, prácticamente ausentes.

En PM-3 la mayor cantidad de restos de vizcacha identificados provienen de las capas intermedias de las unidades excavadas (capas 2 y 3 ) y en particular de la unidad B4, que arrojó la mayor cantidad de restos $(n=298)$, con un mínimo de dos individuos en cada caso, registrándose elementos tanto del esqueleto axial como apendicular. Los camélidos presentan una situación diferente en $\mathrm{PM}-3$, ya que se identificaron principalmente unidades de descarte como huesos cortos (carpos y tarsos), metapodios, falanges, fragmentos de cráneo, mandíbula y molares. Sin embargo, entre los fragmentos no identificadoslos derivados de diáfisis de mamífero grande $(\mathrm{n}=427)$ son más abundantes que los de animales pequeños ( $n=359)$, así como los huesos quemados $(54.8 \%$ vs. $45 \cdot 4 \%)$. Esto podría estar indicando que otras unidades anatómicas de mamíferos grandes fueron ingresadas al sitio, cuyos huesos fueron procesados al extremo, quedando como único registro los derivados de diáfisis. Además, se identificaron especímenes de individuos juveniles, cuyos huesos más frágiles podrían haber incidido en la fragmentación del conjunto. En cambio, en TAN-1 se encuentran presentes unidades de casi todo el esqueleto, lo que estaría indicando que los camélidos habrían sido trasladados completos al sitio. No se registra una cantidad muy elevada de derivados de diáfisis $(n=97)$, por lo que no es posible suponer un procesamiento demasiado intensivo de las carcasas. Finalmente, los pocos especímenes que pudieron adscribirse a un taxón específico corresponden a guanaco (Lama guanicoe), lo que estaría evidenciando que, al igual que en el caso de las vizcachas, estos animales habrían sido caza-

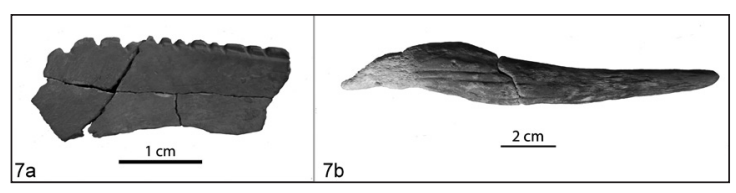

Figura 7. Artefactos óseos: a) Fragmento de artefacto (PM3. Unidad B4, Capa 3); b) Asta de taruca (PM-8, Unidad B4, Capa 2).

dos en las cercanías del sitio, dado que éstos se ubican en un hábitat muy favorable para esta especie.

A diferencia de PM-3 y TAN-1, PM-8 presenta una situación particular por la alta presencia de roedores cricétidos, cuyos restos presentan abundantes huellas de ácidos digestivos, lo que hace suponer que el mayor agente depositacional fue posiblemente un ave rapaz. Se registraron, además, escasos especímenes de camélido correspondientes en su totalidad a fragmentos de molar y un fragmento de asta de taruca. Además, en la Capa 2 de las unidades excavadas en PM-8, se registraron fragmentos de huesos quemados no identificados, lo que evidencia actividad humana.

Entre los artefactos óseos destaca un fragmento de hueso plano hallado en una de las capas intermedias (Capa 3 ) de $\mathrm{PM}-3$, el que presenta un borde denticulado o aserrado, en forma de incisiones transversales paralelas (Figura 7a). El mismo borde presenta una larga incisión longitudinal. En la Capa 2 también se registró un fragmento óseo con pigmento rojo adherido, lo que sugeriría la posibilidad de que este momento estuviera asociado a la elaboración de algunas de las pinturas que se observan en el sitio.

Otro artefacto destacable se refiere a un fragmento de asta de taruca encontrado en la Capa 2 de PM-8. Se trata de un fragmento de cuerpo y extremo distal (punta) bastante meteorizado. En su extremo distal se observa un microastillado que podría estar indicando un uso como probable retocador (Figura $7 \mathrm{~b}$ ). El hecho de que este espécimen se encuentre tan meteorizado en comparación al resto, hace suponer que el asta fue recolectada bastante tiempo después de que ésta se desprendiera del animal o el mismo muriese. Otra posibilidad es que se tratara de un elemento muy apreciado y, por lo mismo, altamente conservado. 


\begin{tabular}{|c|c|c|c|}
\hline Nombre sitio & Sigla fechado & Proveniencia de la muestra & Fecha sin cal. \\
\hline Pampa El Muerto 3 & UGAMS-3041 & PM3-C5 CAPA II-nivel 1-Rasgo 1 $_{1}$ & $430 \pm 25$ \\
\hline Pampa El Muerto 3 & UGAMS-3042 & PM3-C5 CAPA II-nivel 3-Rasgo 2 & $2180 \pm 30$ \\
\hline Pampa El Muerto 3 & UGAMS-3043 & PM3- C5-CAPA III-nivel 1-Rasgo 6 & $2460 \pm 30$ \\
\hline Pampa El Muerto 8 & UGAMS-3039 & PM8- A3-CAPA II-nivel 2 & $5750 \pm 30$ \\
\hline Pampa El Muerto 8 & UGAMS-3040 & PM8- B4-Pozo 1 CAPA II-nivel 1 & $1680 \pm 25$ \\
\hline Tangani 1 & BETA 259165 & Tangani 1- C4- Capa II-nivel 2 & $4170 \pm 40$ \\
\hline Tangani 1 & BETA 259166 & Tangani 1- C4- Capa III-nivel 1 & $4400 \pm 40$ \\
\hline Tangani 1 & BETA 259167 & Tangani 1- D4- Capa II-nivel 5- 65 cm & $5160 \pm 60$ \\
\hline Tangani 1 & BETA 259168 & Tangani 1- D4- Capa II-nivel 5- 80 cm & $790 \pm 40$ \\
\hline
\end{tabular}

Tabla 8. Fechados $\mathrm{C}^{14}$ - AMS obtenidos en los tres aleros con pinturas.

En resumen, se observa en general un comportamiento similar entre todas las unidades y capas analizadas, si bien destaca una mayor intensidad de ocupación en las capas intermedias de los sitios PM-3 y PM-8. Entre los materiales se evidencian dos taxones principales, la vizcacha y los camélidos, los que habrían sido cazados en las cercanías del sitio y consumidos in situ. Al tratarse, en general de muy pocos individuos, es coherente plantear la evidencia de incursiones esporádicas al lugar, aprovechando los recursos de las inmediaciones durante la estadía.

\section{Resultados de las dataciones en los aleros de la precordillera de Arica}

En los tres aleros se obtuvieron nueve dataciones $\mathrm{C}^{14}$ AMS sobre muestras de carbón provenientes de fogones hallados en estratigrafía. Los resultados evidencian un rango de ocupación entre $\mathrm{C}^{14}$-AMS $5750 \pm 30$ y $430 \pm 25$ años AP (sin calibrar) equivalentes a 6640 y 530 años cal. $\mathrm{AP}^{7}$, dando cuenta de un amplio rango cronológico para el uso de los aleros pintados (Tabla 8). Tangani 1, además, parece haber sido ocupado en las últimas décadas, por parte de pastores u otros visitantes, que dejaron latas de conservas que recubren el piso del alero.

Estratigráficamente, en todos los aleros se distinguen niveles de ocupación alternados con niveles estériles co-

\footnotetext{
7 Las fechas $\mathrm{C}^{14}$ fueron calibradas con el programa CALIB 6.0, curva de calibración INTCALog, método probabilidad de medianas con 2 sigmas.
}

rrespondientes a períodos de abandono. En PM-3 tres dataciones de pequeños fogones o eventos de quema muestran que el alero fue visitado varias veces. Las fechas oscilan entre 2710 y 530 años cal. AP, equivalentes a los períodos Formativo (ca. 3700-1500 años AP) e Intermedio Tardío (ca. 800-550 años AP) de la secuencia prehistórica regional. En PM-8, dos fechas que oscilan entre 6640 y 1700 años cal. AP muestran igualmente un amplio rango de ocupación, entre finales del Arcaico Medio (ca. 8000-600o años AP) y el período Medio (ca. 1500-800 años AP). Para este último período no se conocían, hasta ahora, ocupaciones datadas en tierras altas. Finalmente, en TAN-1 las cuatro dataciones obtenidas dan cuenta de una mayor intensidad de ocupación entre 6180 y 780 años cal. AP correspondientes a los períodos Arcaico Tardío (ca. 6000-3700 años AP) e Intermedio Tardío. Al exterior de un muro de pirca construido alrededor de este alero, que permitió su uso reciente como corral, se observa una importante cantidad de fragmentos cerámicos característicos del período Intermedio Tardío local, ocupación no detectada en el subsuelo. Una particularidad de las dataciones de este sitio, se refiere a la obtenida de la unidad $\mathrm{D}_{4}$, Capa 2 nivel 5 obtenida a $80 \mathrm{~cm}($ BETA 259168) y que resulta más reciente a la de la misma unidad, capa y nivel pero a $65 \mathrm{~cm}$ (BETA 259167). La explicación se debe a que estas dos muestras fueron tomadas en dos fogones de distintos sectores de la unidad. Más aún, esta unidad presenta en el sector de la muestra de $80 \mathrm{~cm}$ una cavidad que indica que este fogón pudo ser realizado en épocas más recientes afectando la estratigrafía del alero. 
En general, estas dataciones coinciden con las obtenidas previamente en otros aleros con pinturas como Piñuta, Puxuma, Guañure y Los Dolmenes (Santoro y Chacama 1982, 1984; Santoro y Dauelsberg 1985). En conjunto, todas estas fechas dan cuenta de una ocupación más intensiva de los pisos de prepuna y puna a partir del Arcaico Tardío, la que se prolonga durante el Formativo, esencialmente en su fase temprana. No obstante, recientes dataciones para las fases Arcaico Temprano y Medio muestran un uso de estos aleros desde épocas anteriores (Corvalán et al. $2013 \mathrm{Ms}$ ). Tras este lapso temporal otra importante ocupación da cuenta del uso de los aleros durante los períodos Intermedio Tardío y Tardío, época de importante desarrollo prehispánico en la zona de tierras altas (Muñoz y Chacama 2006).

\section{* Pinturas rupestres: Contextos, CRONOLOGÍA, MOVILIDAD Y TERRITORIALIDAD}

Las evidencias culturales analizadas sugieren que grupos de cazadores acamparon esporádicamente y por breves lapsos en los aleros, como parte de circuitos de movilidad definidos por cierta estacionalidad. En este marco, los aleros sirvieron como campamentos logísticos estacionales para el aprovisionamiento de determinados recursos locales. Esto en consideración a que: 1) la tecnología lítica de talla bifacial estuvo orientada a la elaboración de instrumentos de caza (puntas de proyectil) y al faenamiento de presas (artefactos de uso cortante); 2) se utilizaron las mismas fuentes de aprovisionamiento de materias primas silíceas de diferentes tonalidades; 3 ) más del $50 \%$ de los desechos de talla están fracturados, debido a factores post-depositacionales, como pisoteo, que podría asociarse a reocupaciones sucesivas de los sitios. También es posible que eventos de lluvias estacionales, evidenciado en rasgos de acumulación de material de arrastre detectado en las excavaciones, provocaran la fragmentación del material lítico por arrastre. Adicionalmente, los restos vegetales muestran un uso doméstico de los aleros, a través del consumo de alimentos y el descanso. Destacan como alimentos recolectados del entorno los frutos de cactáceas y los tallos de yuyo consumidos en torno a pequeños fogones donde se descartaron sus semillas, lo que explicaría su alto grado de carbonización. Se agregan productos, tales como las vainas de algarrobo y maíz provenientes de quebradas vecinas de mayor humedad.
La actividad de descanso se realizó sobre piso preparado con capas de paja y hojas suculentas. Finalmente, tanto PM-3 como TAN-1 muestran el consumo de los mismos taxones animales: vizcacha y camélido, cazados en los alrededores y transportados a los sitios.

Las escenas pintadas representadas relativas en su mayoría a escenas de caza de camélidos (Dudognon y Sepúlveda 2013) podrían indicar actividades realizadas en sus inmediaciones, pues se evidencia su consumo en los depósitos. Una vez capturadas y faenadas, las presas serían consumidas in situ, pudiendo también llevarse parte de ellas hacia otros campamentos, hasta ahora no identificados. La representación de escenas de pastoreo podría también dar cuenta de la ocurrencia de este tipo de práctica en torno a los sitios. Por ello, la variabilidad estilística identificada podría vincularse con distintas formas de caza, así como con diferentes estrategias vinculadas con la gestión de los camélidos (caza o pastoreo). No obstante, es posible que los diferentes conjuntos refieran además a variaciones inter-localidades, como las que se visualizan entre los sectores altos de las cuencas de Lluta y Azapa-Tignamar, pero que aún requieren mayor precisión. De momento, solo es posible reconocer que los aleros serían parte de un conjunto de sitios o asentamientos vinculados con la gestión del recurso animal (Sepúlveda et al. $2013 \mathrm{Ms}$ ), aunque no sea factible precisar el patrón de asentamiento completo. En otras palabras, estos sitios formarían parte de un sistema mayor de movilidad con campamentos bases localizados en otros pisos ecológicos, aún no reconocidos.

Consecuentemente, las evidencias disponibles indican que no parece haber habido, a lo largo del tiempo, profundos cambios en la forma de ocupar los aleros PM-1, PM-8 y TAN-1. Así, la funcionalidad de uso como campamentos logísticos de estos sitios habría perdurado por casi 4000 años, desde inicios del Arcaico Tardío hasta el Formativo. Durante esta época, los aleros con pinturas habrían sido ocupados por cazadores recolectores que persistían en este modo de subsistencia, cuando en otras zonas se estructuraban sociedades de vida más aldeana, basada en la agricultura o el pastoreo, y el manejo de ciertas tecnologías como la alfarería, metalurgia, textilería (Santoro y Núñez 2011). Más tarde, en épocas del Intermedio Tardío, estos aleros serían ocupados por grupos de tarea específicos orientados a la caza o 
el pastoreo, gravitando en torno a las aldeas y pucaras que se levantaron en la precordillera (Muñoz y Chacama 2006). El importante número de piezas fracturadas refuerza la idea de reocupación de los sitios por parte de grupos que desarrollan similares actividades.

Pese a las escasas evidencias del Intermedio Tardío, los depósitos de los tres aleros y la información de otros sitios con pinturas de la precordillera del extremo norte de Chile, favorecen la atribución cronológica relativa de este tipo de manifestaciones al Arcaico Tardío y al Formativo (ver también Santoro y Dauelsberg 1985). No obstante, no podemos descartar sobre la base de estas ocupaciones la existencia de representaciones naturalistas desde el Arcaico Temprano, aunque por ahora no se cuente con manifestaciones asociadas a estos primeros poblamientos. La reciente fecha del alero pintado PM15 de $9510 \pm 50$ (BETA-319884, Proyecto FONDECYT 1100354) abre, sin embargo, la discusión en este sentido. La atribución temporal de las pinturas al Arcaico Tardío y Formativo es coincidente con lo observado en toda el área Centro-Sur Andina, cuando se observan mayores cantidad de evidencias y variabilidad estilística en este arte (Yacobaccio et al. 2008). Por ello, pensamos también que es posible que esta profusión de pinturas rupestres se vincule con los cambios de modos de vida característicos de estos períodos en particular, por un lado, con los procesos de domesticación o introducción de plantas y animales tras los cambios climáticos ocurridos durante el Arcaico Medio; por otro lado, con los procesos de complejización de transición hacia el Formativo (Muñoz 2004; Gallardo y Yacobaccio 2005; Yacobaccio 2006; Aldenderfer 2010, 2012; Aldenderfer y Blanco 2011; Craig 2011, 2012; Núñez y Santoro 2011; Marquet et al. 2012; Santoro et al. 2012).

En términos de su distribución espacial, las pinturas atribuidas al primer grupo, con sus dos variantes (GE1-1 y GE1-2) y definido por representaciones de tipo naturalista, se reconocen en todo el piso precordillerano del sur de Perú y norte de Chile. Las semejanzas se refieren al tipo de figuras representadas, sus características formales y técnicas, así como a la composición de los paneles (Aldenderfer 1987 Ms, 1998; Klarich y Aldenderfer 2001; Ayca 2004; Suárez 2012). Las similitudes estilísticas y las ocupaciones registradas en sitios tales como Quelcatani, El Cánido, Vilavilani y varios otros de la cuenca del río Ilave refuerzan la cronología relativa arcaica para las pinturas. Esta contemporaneidad cronológica junto con las semejanzas estilísticas evidencian, por tanto, la conformación de un paisaje cultural común entre la precordillera del sur de Perú y el norte de Chile, establecidos mediante circuitos de "movilidad horizontal precordillerana" o transectas puneñas latitudinales (Schiappacasse y Niemeyer 1975). Las similitudes de la tipología lítica de la región precordillerana del sur de Perú y norte de Chile, especialmente para el Arcaico Temprano y Medio (Klink y Aldenderfer 2005: 53-54), apoyan la idea de construcción de un paisaje cultural común desde épocas tempranas. No obstante, la introducción temprana de elementos provenientes de otros pisos ecológicos, incluyendo fragmentos de conchas de la costa pacífica (Núñez y Santoro 1988, 2011; Castillo 2011), así como inversamente la presencia de recursos y materias primas altoandinas en la costa (Sepúlveda et al. $2013 \mathrm{Ms}$ ), sugieren que los autores de las pinturas u ocupantes de los aleros mantuvieron también estrechas interacciones con grupos situados en otros pisos ecológicos, aunque tampoco puede descartarse que accedieran a ellos directamente en ciertas ocasiones.

A diferencia de las fases tempranas, a partir del Arcaico Tardío, la mayor diversidad tipológica de los conjuntos líticos parece responder a una mayor circunscripción espacial de los cazadores recolectores (Klink y Aldenderfer 2005), pese a mantener variadas formas de movilidad horizontal y vertical. En este escenario es posible que el arte rupestre, más allá de su relación con los procesos de cambios ocurridos desde el Arcaico Tardío y mencionados previamente, haya constituido un marcador espacial, inclusive territorial, para grupos sociales que se articulaban a través de actividades colectivas puntuales, aunque efectivas, de complementariedad, intercambio y solidaridad (Aldenderfer $1987 \mathrm{Ms}$ ). En ese contexto, las pinturas pudieron realizarse para representar y contribuir a actos de caza colectiva de animales durante épocas de agregación social ocasional (Conkey 1980). En consecuencia, a partir del Arcaico Tardío se tejería e intensificaría un complejo entramado o redes de interacción local y regional, en el cual las pinturas rupestres participarían del intercambio y flujo de información (Gamble 1982; Whallon 2006; Gallardo et al. 2012), lo que también podría explicar la variabilidad estilística identificada. En resumen, el estudio de las pinturas rupestres y sus contextos asociados demues- 
tran la importancia de ser abordados en conjunto, pues permite explorar nuevas formas de interpretación y una mayor comprensión de estas formas de expresión visual.

Agradecimientos Trabajo financiado por Proyecto UTA Mayor 3741-12 y realizado en el marco del Proyecto
FONDECYT 1130808. Aquí presentamos los resultados de análisis de materiales obtenidos en temporadas de terreno realizadas entre los años 2006 y 2009 (FONDECYT de Iniciación 11060144). Se agradece de igual forma el apoyo del Convenio de Desempeño Universidad de Tarapacá-MINEDUC.

\section{* Referencias citadas}

ANDREWS, P., 1990. Owls, caves and fossils. Predation, preservation and accumulation of small mammals bones in caves. British Museum of Natural History, Londres.

ALDENDERFER, M., 1987 Ms. Hunter-gatherer settlement dynamics and rupestral art: Inferring mobility and aggregation in the South Central Andes of Southern Peru. Trabajo presentado en VIII International Symposium on American Rock Art, Santo Domingo.

1998. Montane foragers. Asana and the South Central Andean Archaic. University of Iowa Press, Iowa City.

2010. Gimme that old time religion: Rethinking the role of religion in the emergence of social inequality. En Pathways to power. New perspectives on the emergence of social inequality, T. Price y G. Feinman (Eds.), pp. 77-95. Springer, Heidelberg, Berlín, Nueva York.

2012. Balances y perspectivas del período Arcaico en la región del altiplano. En Arqueología de la cuenca del Titicaca, Perú, L. F. Blanco y H. Tantaleán (Eds.), pp. 27-39. Instituto Francés de Estudios Andinos (IFEA) y Cotsen Institute of Arcaheology, UCLA, Lima.

ALDENDERFER, M. y L. FLORES, 2011.Reflexiones para avanzar en los estudios del período Arcaico en los Andes Centro-Sur. Chungara, Revista de Antropología Chilena 43 (vol. especial): 531440 .

ANDREFSKY, W., 1998. Lithics. Macroscopic approachs to analysis. Cambridge University Press, Cambridge.

ASCHERO, C., 1983 Ms. Ensayo para una clasificación morfológica de artefactos líticos. Manuscrito para la cátedra de ergología y tecnología. Departamento de Ciencias Antropológicas, Universidad de Buenos Aires, Buenos Aires.

2001. Figuras humanas, camélidos y espacios en la interacción circumpuneña. En Arte en las rocas. Arte rupestre, menhires y piedras de colores en Argentina, M. Podestá y M. de Hoyos (Eds.), pp. 15-
44. Sociedad Argentina de Antropología, Asociación Amigos del Instituto Nacional de Antropología y Pensamiento Latinoamericano, Buenos Aires.

AYCA, O. R., 2004. El arte rupestre de Vilavilani. Municipalidad Distrital de Palca, Palca-Tacna.

BATE, F., 1971. Material lítico: Metodología de clasificación. Noticiario Mensual del Museo Nacional de Historia Natural 181-182: 3-24.

CARTAJENA, I., 2002. Los conjuntos faunísticos del Arcaico Temprano en la Puna de Atacama, Norte de Chile. Universidad de Berlín, Berlín.

CASTILLO, C., 2011. Aproximación a la movilidad e interacción arcaica en el extremo norte de Chile, a través de objetos "noutilitarios". Memoria para optar al título de Arqueólogo, Universidad de Tarapacá, Arica.

CONKEY, M., 1980. The identification of prehistoric hunter-gatherer aggregation sites: The case of Altamira. Current Anthropology 21(5): 609-630.

CORVALÁN, M., D. OSORIO, C. CASTILLO y M. SEPÚlVEDA, 2013 Ms. Funcionalidad de sitio de los aleros con pintura de la precordillera de Arica (extremo norte de Chile), durante el período Arcaico (10.500-3700 años AP). Una aproximación desde el componente lítico. Manuscrito en poder de los autores.

CRAIG, N., 2011. Cultural dynamics, climate, and landscape in the South-Central Andes during the Mid-Late Holocene: A consideration of two socio-natural perspectives. Chungara, Revista de Antropología Chilena 43(1):367-391.

2012. Transiciones del Arcaico Tardío al Formativo Temprano. Una perspectiva desde la arqueología de la unidad doméstica de dos sitios del valle del río Ilave, cuenca del lago Titicaca. En Arqueología de la cuenca del Titicaca, Perú, L. Blanco y H. Tantaleán (Eds.), pp. 41-130. Instituto Francés de Estudios Andinos (IFEA), Cotsen Institute of Arcaheology, UCLA, Lima. 
DEFRANCE, S. y A. UMIRE, 2004. Quebrada Tacahuay: Un sitio marítimo del Pleistoceno Tardío en la costa sur de Perú. Chungara, Revista de Antropología Chilena 36(2): 257-278.

DUDOGNON, C. y M. SEPÚlVEDA, 2013. Hunting practices in rock art Sierra Arica (far north of Chile). Actas 25th Symposium of Valcamonica. En prensa.

GALLARDO, F., 1996. Acerca de la interpretación en arte rupestre. Boletín de la Sociedad Chilena de Arqueología 32: 31-36.

GALLARDO, F. y H. YACOBACCIO, 2005. Wild or domesticated? Camelids in Early Formative rock art of the Atacama Desert (Northern Chile). Latin American Antiquity 16 (2): 115-130.

GALLARDO, F., G. CABELLO, G. PIMENTEL, M. SEPÚlVEDA y L. CORNEJO, 2012. Flujos de información visual, interacción social y pinturas rupestres en el Desierto de Atacama (Norte de Chile). Estudios Atacameños, Arqueología y Antropología Surandinas 43:35-52.

GAMBLE, C., 1982. Interaccion and alliance in Paleolithic society. Man, New Series 1781: 92-107.

GARCÍA, M. y M. SEPÚLVEDA, 2011. Contextos vegetales asociados a aleros pintados de la precordillera de Arica (extremo norte de Chile). Estudios Atacameños, Arqueología y Antropología Surandinas 41: 97-118.

GRAYSON, D., 1984. Quantitative zooarchaeology. Academic Press, Orlando.

GUFFROY, J., 1999. El arte rupestre del antiguo Perú. Instituto Francés de Estudios Andinos (IFEA) e IRD, Lima.

HOFMANN, A., 1989. Cactáceas en la flora silvestre de Chile. Ediciones Fundación Claudio Gay, Santiago.

HOLMGREN, C., E. ROSELLÓ, C. LATORRE y J. BETANCOURT, 2008. Late-Holocene fossil rodent middens from the Arica region of northernmost Chile. Journal of Arid Environments 72: 677-686.

JOLY, D., R. MARCH y G. MARTÍNEZ, 2005. Étude des ossements brûlés du site Paso Otero 5 (Argentine). Archéosciences. Revue d'Archéométrie 29: 83-93.

KAUFMANN, C., 2009. Estructura de edad y sexo en guanaco. Colección Tesis Doctorales, Sociedad Argentina de Antropología, Buenos Aires.

KLARICH, E. y M. ALDENDERFER, 2001. Qawrankasax waljawa: Arte rupestre de cazadores y pastores en el río Ilave (sur de Perú). Boletín del Museo Chileno de Arte Precolombino 8: 47-58.
KLINK, C. y M. ALDENDERFER, 2005. A projectile point chronology for the south-central Andean highlands. En Advances in Titicaca Basin Archaeology 1, C. Stanish, A. Cohen y M. Aldenderfer (Eds.), pp. 25-54. Cotsen Institute of Archaeology, University of California, Los Angeles.

LATORRE, C., J. BETANCOURT, J. REICH, J. QUADE, C. HOLMGREN, C. PLACZEK, A. MALDONADO, M. VUILLE y K. RYLANDER, 2005. Late Quaternary history of the Atacama Desert. En $23^{\circ}$ S: The archaeology and environmental History of the southern deserts, M. Smith y B. Hesse (Eds.), pp. 73-90. National Museum of Australia Press, Canberra.

LATORRE, C., C. SANTORO, P. UGALDE, E. GAYÓ, D. OSORIO, C. SALAS-EGAÑA, R. DE POL-HOLZ, D. JOLY, y J. $\mathrm{RECH}, 2 \mathrm{Ol3}$. Late Pleistocene human occupation of the hyperarid core in the Atacama Desert, northern Chile. Quaternary Science Reviews. En prensa.

LAVALLÉE, D., 1995. Promesse d'Amérique. La préhistoire de l'Amérique du Sud. Hachette, París.

LAVALLÉE, D., M. JULIEN, P. BÉAREZ, A. BOLAÑOS, M. CARRÉ, A. CHEVALIER, T. DELABARDE, M. FONTUGNE, C. RODRÍGUEZ-LOREDO, L. KLARICH, P. USSELMANN y M. VANHAEREN, 2011. Quebrada de Los Burros. Los primeros pescadores del litoral pacífico en el extremo sur peruano. Chungara, Revista de Antropología Chilena 43: 353-366.

LYMAN, R., 1994. Vertebrate taphonomy. Cambridge Manuals in Archaeology, Cambridge University Press, Cambridge.

MANN F., G., 1978. Los pequeños mamíferos de Chile. Gayana Zoología 40: 1-342.

MARQUET, P., C. SANTORO, C. LATORRE, V. STANDEN, S. ABADES, M. RIVADENEIRA, B. ARRIAZA y M. HOCHBERG, 2012. Emergence of social complexity among coastal hunter-gatherers in the Atacama Desert of northern Chile. PNAS 109(37): $14.754-14.760$.

MENGONI, G., 1999. Cazadores de guanacos de la estepa patagónica. Colección Tesis Doctorales. Sociedad Argentina de Antropología, Buenos Aires.

MORENO A., C. SANTORO y C. LATORRE, 2009. Climate change and human occupation in the northernmost Chilean Altiplano over the last $\sim 11.500$ cal. yr BP. Journal of Quaternary Science 24(4): 373-382.

MOSTNY, G. y H. NIEMEYER, 1983. Arte rupestre de Chile. Serie El Patrimonio Cultural Chileno, Colección Historia del Arte Chileno, Depto. de Extensión del Ministerio de Educación, Santiago. 
MUELLE, J., 1969. Las cuevas y pinturas de Toquepala.Mesa Redonda de Ciencias Prehistóricas y Antropológicas vol. 3: 186-196.

MUELLE, J. y R. RAVINÉS, 1986. Toquepala. En Arte rupestre del Perú. Inventario general, Muelle, J. y R. Ravinés (Eds.), pp. 56-86. Instituto Nacional de Cultura, Lima.

MUÑOZ, A. y C. BONACIC, 2006. Variación estacional de la flora y vegetación en la precordillera andina de la comuna de Putre (I Región de Tarapacá, Chile) durante el período 2002-2003. Gayana Botánica 63(1): 75-92.

MUÑOZ, I., 2004. El período Formativo en los valles del norte de Chile y sur de Perú: Nuevas evidencias y comentarios. Chungara, Revista de Antropología Chilena 36 (1): 213-225.

MUÑOZ, I. y L. BRIONES, 1996. Poblados, rutas y arte rupestre precolombinos de Arica: Descripción y análisis de sistema de organización. Chungara, Revista de Antropología Chilena 28 (1-2): 47-84.

MUÑOZ, I. y J. CHACAMA, 2006. Complejidad social en las alturas de Arica: Territorio, etnicidad y vinculación con el Estado inca. Ediciones Universidad de Tarapacá, Arica.

NIEMEYER, H., 1972. Las pinturas de la Sierra de Arica. Editorial Gerónimo de Bibar, Editorial Universitaria, Santiago.

NOVOA, S., 2006. Sobre el origen de la tuna en el Perú. Algunos alcances. Zonas Áridas 10: 174-181.

NÚÑEZ, L. y C. SANTORO, 1988. Cazadores de la Puna Seca y Salada, norte de Chile. Estudios Atacameños 9: 11-60.

2011. El tránsito arcaico-formativo en la Circumpuna y Valles Occidentales del centro-sur andino: Hacia los cambios "neolíticos". Chungara, Revista de Antropología Chilena 43(1): 487-530.

NÚÑEZ, L., I. CARTAJENA, J. LOO, S. RAMOS, T. CRUZ, y H. RAMÍREZ, 1997. Registro e investigación del arte rupestre en la Cuenca de Atacama (informe preliminar). Estudios Atacameños 14:307-325.

NÚÑEZ, L., I. CARTAJENA, C. CARRASCO y P. DE SOUZA, 2006. Patrones, cronología y distribución del arte rupestre arcaico tardío y formativo temprano en la cuenca de Atacama. En Tramas en la piedra: Producción y usos del arte rupestre, D. Fiore y M. Podestá (Eds.), pp. 191-204. Asociación Amigos del Instituto Nacional de Antropología (AINA), World Archaeological Congress (WAC) y Sociedad Argentina de Antropología. Altuna Impresores, Buenos Aires.
OSORIO, D., D. Jackson, P. Ugalde, C. Latorre, R. De Pol-Holz y C. Santoro, 2011. Hakenasa cave and its relevance for the peopling of the Southern Andean altiplano. Antiquity 85: 11941208.

PARDO, O. y J. PIZARRO, 2005. Especies botánicas consumidas por los chilenos prehispánicos. Colección Chile Precolombino. Editorial Mare Nostrum, Santiago.

REISE, D., 1973 Clave para la determinación de los cráneos de marsupiales y roedores chilenos. Gayana Zoología 27: 1-20.

RODRÍGUEZ, M., 1996-1998. Propuesta metodológica para el análisis de macrovestigios vegetales. Presentación de un caso: Quebrada Seca 3, nivel 2B (12). Palimpsesto 5: 238-248.

SALAZAR, D., D. JACKSON, J. GUENDON, H. SALINAS, D. MORATA, V. FIGUEROA, G. MANRÍQUEZ y V. CASTRO, 2011. Early evidence (ca. 12.000 BP) for iron oxide mining on the Pacific coast of South America. Current Anthropology 52:463475 .

SANDWEISS, D., 2003. Terminal Pleistocene through MidHolocene archaeological sites as paleoclimatic archives for the Peruvian coast. Palaeogeography, Palaeoclimatology, Palaeoecology 194: $23-40$

SANTORO, C., 1989. Antiguos cazadores de la puna (9000 a 6000 AC). En Culturas de Chile. Prehistoria. Desde sus orígenes hasta los albores de la Conquista, J. Hidalgo, V. Schiappacasse, H. Niemeyer, C. Aldunate e I. Solimano (Eds.), pp.33-56. Editorial Andrés Bello, Santiago.

SANTORO, C. y J. CHACAMA, 1982. Secuencia cultural de las tierras altas del área Centro-Sur Andina. Chungara 9: 22-45.

1984. Secuencia de asentamientos precerámicos del extremo norte de Chile. Estudios Atacameños 7: 85-103.

SANTORO, C. y P. DAUELSBERG, 1985. Identificación de indicadores tempo-culturales en el arte rupestre del extremo norte de Chile. En Estudios en arte rupestre. Primeras jornadas de arte y arqueología, C. Aldunate, J. Berenguer y V. Castro (Eds.), pp. 6986. Museo Chileno de Arte Precolombino, Santiago.

SANTORO, C. y C. LATORRE, 2009. Propuesta metodológica interdisciplinaria para poblamientos humanos Pleistoceno Tardío/Holoceno Temprano, precordillera de Arica, Desierto de Atacama Norte. Andes 7: 11-35.

SANTORO, C. y L. NÚÑEZ, 1987. Hunters of the Dry Puna and the Salt Puna in northern Chile. Andean Past 1: 57-109. 
SANTORO, C., M. RIVADENEIRA, C. LATORRE, F. ROTHHAMMER y V. STANDEN, 2012. Rise and decline of Chinchorro sacred landscapes along the hyperarid coast of the Atacama Desert. Chungara, Revista de Antropología Chilena 44(4): 637-653.

SCHIAPPACASSE, V. y H. NIEMEYER, 1975. Apuntes para el estudio de la transhumancia en el valle de Camarones (provincia de Tarapacá, Chile). Estudios Atacameños 3: 49- 52.

1996. Las pictografías de los aleros de Itiza y de Mullipungo de la Sierra de Arica. Chungara 28 (1-2): 253-276.

SEPÚLVEDA, M., 2008. Pinturas rupestres de la precordillera de Arica (norte de Chile). Re-evaluación a 40 años de la obra pionera de Hans Niemeyer. Boletín SIARB 22: 68-79.

2011. La Tradition Naturaliste des peintures rupestres des groupes chasseurs cueilleurs de l'extreme nord du Chili. En Peuplement et préhistoire en Amérique, D. Vialou (Ed.), pp. 453-464. Comité des Travaux Historiques et Scientifiques, París.

SEPÚLVEDA, M., T. SAINTENOY y W. FAÚNDEZ, 2010. Rock paintings of the precordillera region of northern Chile. Rock Art Research 27(2): 161-175.

SEPÚlVEDA, M., T. SAINTENOY y C. DUdOGNON. 2013 Ms. Ensayo de análisis locacional de los sitios de pinturas rupestres de la precordillera del extremo norte de Chile. Manuscrito en poder de los autores.

STAFFORD, M., G. Frison, D. Stanford y G. Zeimans, 2003. Digging for the color of life: Paleoindian red ochre mining at the Powars II site, Platte County, Wyoming, U.S.A. Geoarchaeology: an International Journal 18: 71-90.

SUÁREZ, M., 2012. El cánido: Cazadores de camélidos y pinturas rupestres de Vilavilani. Una aproximación a la ocupación huma- na arcaica y formativa en Palca, Departamento de Tacna, Perú. Tesis para optar al grado de Licenciada en Arqueología. Escuela Profesional de Arqueología y Antropología, Universidad Nacional Federico Villarreal, Lima.

UGALDE, P., C. SALAS, C. LATORRE, D. OSORIO, D. JACKSON y C. SANTORO, 2012. Poblamiento temprano del norte de Chile ( $\left.18-25^{\circ} \mathrm{S}\right)$ : Nuevas evidencias arqueológicas y paleoambientales. Actas del XVIII Congreso Nacional de Arqueología Chilena, pp. 197-206. Valparaíso (2010).

VILLAGRÁN, C. y V. CASTRO, 2004. Ciencia indígena de los Andes del norte de Chile. Editorial Universitaria, Santiago.

VILLAGRÁN, C., M. KALIN y J. ARMESTO, 1982. La vegetación de un transecto altitudinal en los Andes del norte de Chile (18191S). En El ambiente natural y las poblaciones humanas de los Andes del norte de Chile (Arica, Lat. 181280S), vol. 1, Veloso, A. y E. Bustos (Eds.), pp. 13-69. Rostlac, Montevideo.

VILLAGRÁN, C., V. CASTRO, G. SÁNCHEZ, F. HINOJOSA y C. LATORRE, 1999. La Tradición Altiplánica: Estudio etnobotánico en los Andes de Iquique, Primera Región, Chile. Chungara 31(1): 81-186.

WHALLON, R., 2006. Social network and information: Non "utilitarian" mobility among hunter-gahterers. Journal of Anthropological Archaeology 25: 259-270.

YACOBACCIO, H., 2006. Intensificación económica y complejidad social en cazadores recolectores surandinos. Boletín de Arqueología PUCP 10: 305-320.

YACOBACCIO, H., M. CATÁ, M. SOLÁ y M. ALONSO, 2008. Estudio arqueológico y físico-químico de pinturas rupestres en Hornillos 2 (Puna de Jujuy). Estudios Atacameños, Arqueología y Antropología Surandinas 36: 5-28. 